\section{Response to: 'Increasing the threshold for patient global assessment in defining remission may have a different impact in patients with early and established rheumatoid arthritis' by Bugatti et al}

We thank Bugatti et al for their interest in our paper and for sharing their results on applying a $2 \mathrm{~cm}$ cut-off for the patient global assessment (PGA) criterion of the Boolean remission criteria for rheumatoid arthritis (RA) within the setting of a real-world database, ${ }^{1}$ which confirm the data presented in our recent report based on a clinical trial population. ${ }^{2}$ An appropriate definition for remission is of utmost relevance to prevent structural progression or functional deterioration, regardless of the treatment regimen used; in fact, such a definition is clearly needed in clinical practice, where today a significant proportion of patients is able to attain very good control of disease activity. $^{3-6}$ The currently used provisional ACR/EULAR remission should be revisited to no longer be provisional. ${ }^{7}$ Ideally, the definition of remission should be applicable to all people with RA independent of disease duration.

Since more patients fulfil the index-based remission definition (15\% in early RA, and 6.8\% in established RA at 6 months) compared with Boolean remission $(12.4 \%$ and $5.9 \%$, respectively), in our original study we investigated at which cutpoints of the PGA in Boolean criteria there was best agreement with index-based remission definition (simplified disease activity index (SDAI) $\leq 3.3$ ). While Bugatti et al have shown many similarities in the performance of our proposed $2 \mathrm{~cm}$ PGA cut-off using realworld data to those we reported using trial data, ${ }^{2}$ they did not analyse their data in a way that permits them to assess agreement of different Boolean definitions with the SDAI definition of remission, and were therefore not enabled to draw respective conclusions. In terms of analysing agreement, Bugatti et al needed to look at one group that met original Boolean definitions and another that met the expanded definition (this latter group also includes those who meet the original Boolean definition). Bugatti et al rather, as noted in a footnote to their table 1, examined the stratum that had higher PGA assessments separately. Given the close association of PGA with pain and function, ${ }^{8}$ it is expected that those with higher PGA's would have more pain and have worse health assessment questionnaire (HAQ) scores.

We have been conservative in the interpretation of comparative analyses in non-overlapping remission groups (using the different PGA cut-points) since sample size was rather small. The exact number of people in Boolean 2.0 remission is unfortunately not depicted in Bugatti et al nor is the rate of people in Boolean remission. Taking into account that the transition of the PGA cut-off to $2 \mathrm{~cm}$ led to an increase of a bit more than $4 \%$ of remitters makes it possible to convey that only few patients could be accounted to the discrete group of Boolean 2.0 remitters, which may affect performance of kappa statistics applied to this stratum.

We did not recommend a Boolean definition using solely this stratum but rather an expanded Boolean definition that included those who met the original definition and liberalised this definition to include those with slightly higher PGAs. Bugatti et al should have performed agreement analyses using this expanded definition, a definition that includes those who met the original Boolean definition, as it would apply in the clinical setting.

Overall, these published findings should make us more confident that in trials as well as clinical practice a PGA cut-off of 2 out of 10 can be used in evaluation of Boolean remission.
Paul Studenic $\odot,{ }^{1}$ David T Felson $\odot$, ${ }^{2,3}$ Maarten de Wit $\odot{ }^{4}$ Josef S Smolen, ${ }^{1}$ Daniel Aletaha ${ }^{1}$

${ }^{1}$ Department of Internal Medicine 3, Division of Rheumatology, Medical University of Vienna, Wien, Austria

${ }^{2}$ Section of Rheumatology, Boston University School of Medicine, Boston, Massachusetts, USA

${ }^{3}$ Centre for Epidemiology, The University of Manchester, Manchester, UK

${ }^{4}$ Standing Committee of People with Arthritis/Rheumatism in Europe (PARE), EULAR, Zurich, Switzerland

Correspondence to Professor Daniel Aletaha, Department of Internal Medicine 3, Division of Rheumatology, Medical University of Vienna, Wien 1090, Austria; daniel.aletaha@meduniwien.ac.at

Twitter Paul Studenic @Stiddyo

Acknowledgements We thank Abbvie and Centocor (Janssen) for kindly providing patient level data.

Contributors Analyses of data: PS. Interpretation of data: PS, DF, MdW, JSS and DA. Drafting the manuscript: PS and DA. Editing and revision of the manuscript: PS, DF, MdW, JSS and DA.

Funding The authors have not declared a specific grant for this research from any funding agency in the public, commercial or not-for-profit sectors.

Competing interests None declared.

Patient and public involvement Patient research partner MdW was involved in editing, revising and approving this manuscript.

Patient consent for publication Not required.

Ethics approval No additional review board approval was obtained due to secondary data analysis of pooled clinical trial data.

Provenance and peer review Commissioned; internally peer reviewed.

(c) Author(s) (or their employer(s)) 2020. No commercial re-use. See rights and permissions. Published by BMJ.

\section{(A) Check for updates}

To cite Studenic $\mathrm{P}$, Felson DT, de Wit M, et al. Ann Rheum Dis Epub ahead of print: [please include Day Month Year]. doi:10.1136/annrheumdis-2020-217705

Received 21 April 2020

Accepted 24 April 2020

\section{Linked}

- https://doi.org/10.1136/annrheumdis-2020-217488

Ann Rheum Dis 2020;0:1. doi:10.1136/annrheumdis-2020-217705

\section{ORCID iDs}

Paul Studenic http://orcid.org/0000-0002-8895-6941

David T Felson http://orcid.org/0000-0002-2668-2447

Maarten de Wit http://orcid.org/0000-0002-8428-6354

\section{REFERENCES}

1 Bugatti S, De Stefano L, Favalli EG, et al. Increasing the threshold for patient global assessment in defining remission may have a different impact in patients with early and established rheumatoid arthritis. Ann Rheum Dis 2020:annrheumdis-2020-217488.

2 Studenic P, Felson D, de Wit M, et al. Testing different thresholds for patient global assessment in defining remission for rheumatoid arthritis: are the current ACR/EULAR Boolean criteria optimal? Ann Rheum Dis 2020;79:445-52.

3 Singh JA, Saag KG, Bridges SL, et al. 2015 American College of rheumatology guideline for the treatment of rheumatoid arthritis. Arthritis Rheumatol 2016:68:1-26.

4 Smolen JS, Breedveld FC, Burmester GR, et al. Treating rheumatoid arthritis to target: 2014 update of the recommendations of an international Task force. Ann Rheum Dis 2016;75:3-15.

5 Smolen JS, Landewé RBM, Bij|sma JWJ, et al. EULAR recommendations for the management of rheumatoid arthritis with synthetic and biological disease-modifying antirheumatic drugs: 2019 update. Ann Rheum Dis 2020:annrheumdis-2019-216655.

6 Ramiro S, Landewé RB, van der Heijde D, et al. Is treat-to-target really working in rheumatoid arthritis? A longitudinal analysis of a cohort of patients treated in daily practice (RA BIODAM). Ann Rheum Dis 2020;79:453-9.

7 Felson DT, Smolen JS, Wells G, et al. American College of Rheumatology/European League against rheumatism provisional definition of remission in rheumatoid arthritis for clinical trials. Ann Rheum Dis 2011;70:404-13.

8 Studenic P, Radner H, Smolen JS, et al. Discrepancies between patients and physicians in their perceptions of rheumatoid arthritis disease activity. Arthritis Rheum 2012;64:2814-23. 